\title{
The clinical use of quantitative EEG in cognitive disorders
}

\author{
Paulo Afonso de Medeiros Kanda, Renato Anghinah, \\ Magali Taino Smidth, Jorge Mario Silva
}

\begin{abstract}
The primary diagnosis of most cognitive disorders is clinically based, but the EEG plays a role in evaluating, classifying and following some of these disorders. There is an ongoing debate over routine use of qEEG. Although many findings regarding the clinical use of quantitative EEG are awaiting validation by independent investigators while confirmatory clinical follow-up studies are also needed, qEEG can be cautiously used by a skilled neurophysiologist in cognitive dysfunctions to improve the analysis of background activity, slow/ fast focal activity, subtle asymmetries, spikes and waves, as well as in longitudinal follow-ups.

Key words: quantitative EEG, mental disorder, power spectrum, Coherence, neurodegenerative disorder, brain mapping.
\end{abstract}

\begin{abstract}
A utilização clínica do EEG quantitativo nos transtornos cognitivos
Resumo - O uso clínico do EEG Quantitativo nas doenças cognitivas. O diagnóstico das doenças cognitivas geralmente é clínico mas o EEG é importante como exame auxiliar na avaliação, diagnóstico e classificação de algumas delas. O debate atual refere-se ao uso clínico do EEGq. Embora muitos achados no EEGq ainda aguardem validação, o EEGq pode ser usado cautelosamente em situações específicas e por um neurofisiologista experiente. Nas doenças cognitivas ele pode contribuir na análise da atividade de base, em atividades focais lentas ou rápidas, assimetrias sutís, pontas e ondas e no acompanhamento longitudinal dos pacientes.

Palavras-chave: EEG quantitativo, transtorno mental, potencia do espectro, Coerência, doenças neurodegenerativas, mapeamento cerebral.
\end{abstract}

\section{Introduction}

The primary diagnosis of most cognitive disorders is clinically based but the EEG plays a role in evaluating, classifying and following some of these disorders. The EEG is a widely accepted method for evaluating cortical information processing and neurophysiologic changes that occur during unconsciousness and varying states of conscious awareness. Moreover, it is now possible to increase EEG sensitivity through the use of Digital EEG (dEEG) and the mathematical procedures implemented in quantitative EEG (qEEG).

\section{$D E E G$ differs from $q E E G$}

DEEG is defined by the American Academy of Neurology (AAN) as the computer-based paperless acquisition and recording of EEGs, with storage in digital format on electronic media, and waveform display on an electronic monitor or other computer output device. In addition, the AAN ratifies that digital EEG is an established substitute for recording, reviewing, and storing a paper EEG record. It is a clear technical advance over previous paper methods and is highly recommended. (Class III evidence, Type $\mathrm{C}$ recommendation).,

\section{qEEG: the controversy}

There is currently debate over routine use of qEEG. The AAN defines qEEG as the mathematical processing of dEEG to highlight specific waveform components, to transform EEGs into a format or domain that elucidates relevant information, or to associate numerical results with EEG data for subsequent review or comparison. ${ }^{3}$ Signal analysis includes: automated event detection, monitoring

Reference Center of Behavioral and Cognitive Disorders of Clinicas Hospital of the University of São Paulo School of Medicine, São Paulo, SP, Brazil.

Renato Anghinah - Laboratory of Clinical Neurophysiology, CEREDIC, Faculty of Medicine, University of São Paulo - Rua Itacolomi 333 / cj 83 - 01239 020 São Paulo SP - Brazil. E-mail: anghinah@usp.br

Disclosure: The authors report no conflicts of interest.

Received June 5, 2009. Accepted in final form August 19, 2009. 
in the Intensive Care Unit (ICU), source analysis, frequency analysis, statistical analysis and topographic EEG displays. ${ }^{4}$

Unfortunately, clinical use of qEEG can be problematic particularly in the hands of untrained operators. The statistical results can be influenced by wrong electrode placement, artifact contamination, inadequate band filtering, drowsiness, comparisons using incorrect control data bases, and choice of epochs. ${ }^{5}$ Furthermore, statistical processing can yield a large numbers of statistical abnormalities, not all of which are of clinical relevance. These are some reasons, despite the volume of published data, that the clinical usefulness of qEEG remains controversial.

Nevertheless, despite the fact that many findings concerning the clinical use of qEEG are awaiting validation by independent investigators, and that confirmatory clinical follow-up studies are needed, qEEG can be cautiously used by a skilled neurophysiologist in cognitive dysfunctions to improve the analysis of background activity, slow/fast focal activity, subtle asymmetries, spikes and waves, as well as in longitudinal follow-ups. Although some cooperation from most patients is needed, EEG has high test-retest reliability and reflects physiological cortical function where these properties render qEEG frequency change measurements both a practical and useful adjunct to neuropsychological tests. The question remains as to whether qEEG constitutes an investigational method or can be considered an established addition to dEEG in routine clinical use.

This aim of this paper was not to provide a comprehensive review of qEEG literature but to briefly discuss selected topics on the practical clinical use of qEEG in disturbances of consciousness. The topics of evoked potentials and epilepsies are beyond the scope of this paper.

The qEEG can explore physiological and pathological correlates of conditions where consciousness is normal ${ }^{6}$ or impaired, quantifying the increase in low-frequency components of the background activity ${ }^{7,8}$ using coherence analysis to study the neural network functional state. ${ }^{9}$ The method can compare groups of diseases using power spectra ${ }^{10}$ and apply three-dimensional source localization methods to identify the generators of pathological EEG activity. ${ }^{11}$ Thus, there is a broad range of applications where qEEG can be used as a tool to improve clinical diagnosis, evaluation and conduct: encephalopathies; delirium; learning disabilities; attention disorders; mood disorders; ICU monitoring and dementia.

\section{Encephalopathies and delirium}

Quantitative EEG is described as a tool for evaluating encephalopathies associated to diverse causes including Creutzfeldt-Jakob disease, ${ }^{12,13}$ uremic, ${ }^{14}$ hypoxicischaemic, ${ }^{15}$ hepatic, ${ }^{16-18}$ methamphetamine abstinence, ${ }^{19}$ baclofen overdose, ${ }^{20}$ acute lymphoblastic leukemia ${ }^{21}$ and coma. ${ }^{22}$ The method was also used to describe encephalopathy associated to poisoning in the Chernobyl accident. ${ }^{23}$

The encephalopathies are frequently accompanied by delirium which is, in most cases, symptomatic of a serious underlying disease. Thus, the diagnosis of the delirium is critical and urgent because of life-threatening medical complications associated with its high morbidity and mortality. As delirium often goes undiagnosed or misdiagnosed, qEEG has considerable potential in several specific groups, not only for confirming the clinical diagnosis of an organic syndrome, but for distinguishing delirium from dementia. Relative power in the alpha frequency band enables qEEG to distinguish normal from encephalopathic subjects. The variables best able to distinguish delirious from non-delirious patients include the amount of EEG theta activity, relative power in the delta frequency band, and the amount of activity in the slow wave bands compared to the alpha band. ${ }^{24-26}$

In sum, there is a considerable reference list on the subject. However, the views of the American Academy of Neurology (AAN) and the Brazilian Neurophysiology Society (SBNC) on the issue should be considered. According to the AAN and SBNC and based on Class II and III evidence, the frequency analysis, in expert hands, may be a useful complement to the EEG in encephalopathies in cases where the diagnosis remains unresolved. ${ }^{3,4}$

\section{Learning disorders}

Many studies have shown the value of qEEG in complementing the investigation of learning disabilities ${ }^{27,28}$ and evaluating learning disorders, where qEEG discriminant accuracy ranged from $46 \%$ to $98 \% .{ }^{29}$ The models studying the correlations between intelligence and EEG measures can be tested by two categories of EEG parameters: 1 . EEG power and; 2. EEG network properties such as coherence and phase delays and non-linear dynamical models of network complexity.

\section{EEG power}

In a neurophysiological sense, EEG power represents the sum of neurons discharging synchronously. The thickness of the cortical layer is positively correlated with intelligence so it is possible that EEG power may also be a measure that reflects the capacity or performance of cortical information processing. This occurs in a complex and partly non-linear fashion, and is influenced by a variety of factors such as the thickness of the skull, cerebrospinal fluid, inter-electrode distance and age. ${ }^{30}$ Despite these facts, some EEG power studies using LORETA and surface EEG reported a positive correlation between IQ and increased 
absolute alpha and beta band power, ${ }^{31}$ and decreased delta and theta band power. ${ }^{32}$ Further, some EEG network studies have argued that increased complexity and neural efficiency are positively related to intelligence. ${ }^{33-35}$ Thus, there is a negative correlation between EEG coherence and IQ especially in the frontal lobes. ${ }^{36,37}$

Therefore, a continuum of relationships between EEG and cognitive function have been reported in some studies, which have shown significant correlation between EEG and intelligence thus demonstrating predictive validity between EEG and neuropsychological performance. ${ }^{33,38,39}$ In general, the higher the absolute amplitude or power of the EEG then the higher the $\mathrm{IQ}^{37,40}$. Also, the higher the severity of the learning disability, the greater the qEEG clinically-significant abnormalities ${ }^{41,42}$ where high value of slow power is associated with low IQ.43

Relationship between EEG coherence and intelligence Coherence is an amplitude-independent measure that analyses the phase consistency between two time series and the network properties of a system. Low coherence is positively correlated with IQ and is a predictor of IQ. ${ }^{43,44}$ This indicates that the more complex the neural network, the higher the spatial differentiation, with lower coherence between different neuron pathways. ${ }^{45}$

\section{EEG phase 'delay' and intelligence}

Phase angle is the lag delay between two time series (in this case sets of electrodes) and varies as a function of electrode distance and independently of the amplitude of the two time series, where the ability to synchronize distributed generators is significant while the number of connections or strength of connections may have less relevance. The limit of the shortest phase is equal to 0 or near-zero and the studies of frontal lobe phase delay have shown that the shorter the phase delay, the higher the IQ. ${ }^{29,46,47}$ The position of the American Neuropsychiatric Association (ANA) ${ }^{29}$ is that qEEG is capable of providing accurate probability estimates of the likelihood that a given patient has attentional or learning disabilities, on the basis of several replicated studies, if the individual patient assessed matches the selection criteria of the patient group used to form the discriminant. In contrast, the AAN and SBNC deem the qEEG an investigational tool for clinical use in learning disability (Class II and III evidence, Type D recommendation). ${ }^{3,4}$

\section{Attentional disorders}

Attention-deficit hyperactivity disorder (ADHD) is a common neuropsychological disorder of childhood affecting $3-5 \%$ of school-aged children. ${ }^{29}$ Consequently, there is great interest in developing an accurate neurophysiologic diagnostic test differentiating ADHD from normality and other pediatric mental disorders. A literature search on MEDLINE (1997 through 2008) examining EEG associated with the terms "attention deficit" or "hyperactivity" or" hyperkinetic" retrieved 1214 articles, and there are promising results. For instance, children and adults diagnosed with ADHD have high slow-wave power (delta and theta) and children and adolescents with ADHD seem to have reduced beta power compared with their respective normal controls. ${ }^{48-50}$

Meta-analytic results support an ADHD trait of $\mathrm{Cz}$ electrode (eyes-open, fixed-gaze) theta/beta ratio increase in comparison to controls yielding $86-90 \%$ sensitivity and $94-98 \%$ specificity. ${ }^{51}$ Despite this, the generalization of the results is limited because theta/beta changes and increased theta can be found in other neurologic and psychiatric conditions. Thus, the emphasis may be on the integration of the EEG as supplemental information in the complete clinical picture. ${ }^{52}$ This means that among ADHD patients there is an increased theta/beta ratio but not all patients with this trait are candidates for ADHD. Given these limitations, controversy remains where the ANA favors the clinical use of qEEG in $\mathrm{ADHD}^{29}$ while the AAN and the SBNC are against its routine clinical use (Class II and III evidence, Type $\mathrm{D}$ recommendation). ${ }^{3,4}$

\section{Mood disorders \\ Depression}

Conventional EEG (or dEEG), per se, shows from 20\% to $40 \%$ abnormalities in depressed patients. Although unspecific, these changes help in differentiating a normal or nearly normal EEG of depression from a similarly impaired patient with severe EEG slowing suggestive of functional or structural decline regardless of diagnosis. Therefore, an abnormal EEG can identify patients at greater risk for functional decline. Consequently, it can be a useful tool for evaluating depression. ${ }^{53}$ Furthermore, there are a considerable number of publications investigating $\mathrm{qEEG}$ in depression, and some studies were replicated across academic institutions ${ }^{54}$. Among the trait markers is frontal alpha asymmetry, ${ }^{5,56}$ changes in frontal qEEG cordance, ${ }^{57,58}$ asymmetry in frontotemporal slow-wave activity, ${ }^{59}$ decreased inter-hemispheric coherence in the delta and/or theta frequency bands, ${ }^{60,61}$ increased delta and theta bipolar absolute powers of the right hemisphere, ${ }^{62}$ higher percentage of theta in posterior brain areas ${ }^{63}$ and changes in beta activity. ${ }^{64-66}$ The accuracy of these qEEG findings in detecting depression has been demonstrated and replicated in large samples with $72-93 \%$ sensitivity and $75-88 \%$ specificity. ${ }^{29}$ Some caution must be exercised, however, in generalizing results, 
because of the great number of possible psychiatric diagnostic subcategories into which a patient might be placed, and due to the use of antidepressant medication and lack of a standardized methodology. The ANA recommends the use of qEEG as an additional tool classifying unipolar and bipolar patients, differentiating between healthy and depressed individuals, and for distinguishing depression from cases of dementia, schizophrenia, and alcoholism. ${ }^{29}$ The AAN and SBNC, on the contrary, have a more reserved view and state that in depression, qEEG remains investigational (Class II and III evidence, Type D recommendation).,

\section{Panic disorder, schizophrenia, obsessive-compulsive} disorder and anxiety

At present the clinical usefulness of quantitative spectral analysis of the EEG (QEEG) in the diagnosis of these psychiatric conditions remains controversial, based on the lack of "Class I evidence or overwhelming Class II evidence".,

\section{Intensive care unit (ICU) and operating room (OR) monitoring}

Spectral analysis may supplement dEEG in situations when a graphic display can identify and clinically measure changes more reliably. ${ }^{3}$ Carotid endarterectomy, continuous monitoring for early detection of acute intracranial complication during cerebrovascular surgery and other situations where the cerebral blood flow is compromised, are examples. qEEG has shown its value in the early diagnosis and management of severe acute cerebral infarctions and post-SAH vasospasms. In comatose patients, it can provide diagnostic and prognostic information which is otherwise unobtainable. ${ }^{67}$ qEEG seems to be useful for helping clinicians to decide the optimal time-point to disconnect the patient from the ventilator. ${ }^{68}$ The mathematical tools of the qEEG reduce evaluation time of the recorded exam whereas spectral analysis allows bedside non-expert staff to recognize EEG changes in a timely fashion. ${ }^{69,70}$ Therefore, the AAN and SBNC suggest the use of qEEG in ICU patients at high risk for ischemic stroke, acute intracranial bleed, vasospasm, critically elevated intracranial pressure (ICP), or related ischemia, detection and management of convulsive and non-convulsive status epilepticus in high-risk patients, titration of barbiturates, anti-epileptics given for non-convulsive status and mannitol given for increased ICP. On the basis of considerable Class II evidence, EEG seizure detection and frequency analysis is considered an established option when used as an adjunct to routine or digital EEG for continuous brain monitoring by frequency trending in the OR or ICU to detect early acute intracranial complications, and for screening for possible epileptic seizures in high-risk ICU patients (Type B recommendation). ${ }^{3,4}$

\section{Dementia}

Visual analysis of EEG is a helpful auxiliary method in Alzheimer's disease (AD) diagnosis. ${ }^{4}$ The most frequent EEG findings are the displacement of background frequency into delta and theta ranges and the decrease or dropout of alpha central frequency. ${ }^{71}$ However, these EEG changes usually occur in moderate and advanced stages of the disease. Accordingly, ${ }^{72}$ an inverse correlation between the degree of cognitive impairment and the power of low frequency electrical activity in the EEG was observed. Since the first studies of $\mathrm{qEEG},{ }^{73,74}$ the spectral analysis and other statistics have been applied to EEG. A decrease in alpha and beta activities have been observed in various studies published over the last decade. ${ }^{75-77}$ Furthermore, the "alpha like" rhythm could be a diagnostic marker, ${ }^{77}$ since there is a decrease of the alpha frequency to $6.0-8.0 \mathrm{~Hz}$ in mild $\mathrm{AD}$ patients. Another high sensitivity aspect in $\mathrm{qEEG}$ is the background spectral analysis that agrees strongly with the clinical diagnosis of AD. The sensitivity of the spectral analysis ranges from $71 \%$ to $81 \%$ in several studies ${ }^{75,78-80}$ and the spectral analysis also presents strong correlations with neuropsychological tests. ${ }^{80}$ Another qEEG tool is called Coherence (Coh) Analysis, which evaluates the level of covariance between spectral measures obtained by any given pair of electrodes. High Coh has been considered evidence of structural and functional connections between brain cortical areas. ${ }^{81}$ Coh studies aid understanding of the functional relationships among brain areas, which may vary under different conditions. Among alternative techniques for studying relationships between brain areas, Coh is a well established method, used in the quantification of hemispheric connectivity "through the corpus callosum", both in awake and sleeping patients..$^{82,83}$ Leuchter and colleagues $^{84}$ studied $\mathrm{AD}$ and $\mathrm{VaD}$ patients comparing them to control subjects, and found decreases in Coh in both $\mathrm{AD}$ and $\mathrm{VaD}$. Besthorn et al. ${ }^{85}$ studied 50 patients with $\mathrm{AD}$ and found a decrease in Coh in theta, alpha and beta bands versus control subjects, in central and frontal areas. Their findings were comparable to results of Locatelli et al. ${ }^{86}$ who showed an alpha band Coh decrease in $\mathrm{AD}$ in left temporoparieto-occipital areas. The Brazilian Medical Association (AMB) and Brazilian Clinical Neurophysiology Society (SBNC) 2008 guideline refers to the conventional EEG as an established instrument in the evaluation of dementias (Type B recommendation). In addition, frequency analysis ( $\mathrm{qEEG}$ ) is a useful tool to improve the detection of slow waves (Type $B$ recommendation). It can show an increase of theta waves and decrease of alpha and beta waves in $\mathrm{AD}$ patients compared with normal subjects (Type B recommendation). Frequency analysis also has predictive value concerning the development of cognitive impairment in- 
dependently from clinical parameters (Type $\mathrm{C}$ recommendation). Moreover, there is a strong correlation between some qEEG dipole sources characteristics (from the usual EEG bands) and cognitive functions quantified on some specific $\mathrm{AD}$ evaluation scales (Type $\mathrm{B}$ recommendation). The combined use of such qEEG parameters and cognitive scales is recommended to improve the detection of dementia (Type B recommendation). qEEG can be used as a tool in dementias in much the same way as Single photon emission computed tomography (SPECT) (Type $B$ recommendation) and MRI (Type A recommendation). These methods are not mutually exclusive, but rather, are complementary. ${ }^{87}$

\section{qEEG pitfalls and caveats}

qEEG abnormal patterns can be regarded as a specific sign of brain dysfunction. Further, delta and theta slowing are frequently associated with cortical atrophy. However, the same qEEG abnormalities can be found in many different disorders. Quasi pathognomonic patterns of any specific disorder are a rare occurrence. Nevertheless, EEG is an integral part of the diagnostic process in many diseases. Consequently, several qEEG systems have been approved by the U.S. Food and Drug Administration (FDA) for the post-hoc analysis of EEGs and are classified as Class II devices. ${ }^{88}$ In addition, a literature search on the MEDLINE database (1997 through 2008) using the terms quantitative EEG or qEEG retrieved 1545 articles. So, in spite of this volume of published data, why is the method not widely used, at least among neurologists? At present, there are legitimate scientific debates and differences of opinion concerning some uses of qEEG for a multitude of reasons.

Firstly, because there is a lack of a paradigm or unified methodology to handle the huge amounts of data generated when the EEG is recorded. Each researcher has their own mathematical tools hampering comparison of results among laboratories. This incompatibility prevents the formation of a new, coherent and interchangeable knowledge data base as has occurred in dEEG. Secondly, one of the major problems in electroencephalography is the intra/ inter-subject variability. Unfortunately, the EEG is subject to great variability depending on biological (age, vigilance, thickness of tissues), technical (AC or DC current equipment, electrodes, gel characteristics, impedances) and artifactual issues. Ideally, a feature should be stable and recur in the same and other patients in order to be of clinical use. Therefore, in the qEEG field each new postulate requires large dataset to allow a full investigation to be carried out. Thirdly, it is not difficult to group individuals with the same diagnoses and to then find electroencephalographic similarities among them. More challenging however, is to select an individual randomly and match them with a given group. Thus, the aim of this technology could be, instead of providing diagnoses, to complement the findings of a given diagnosis and to aid follow-up in specific cases. Last but not least, electroencephalography is a very specific field in which years are required to become a specialist. Thus, it is often difficult for professionals other than neurophysiologists to make sense of all the charts and tables generated by the up-to-the-minute software available.

In sum, clinical diagnosis of cognitive dysfunction is a complex process depending on multiple sources of information. Taking this into account, computer-assisted diagnosis using qEEG is an accurate, inexpensive, easy to handle tool that represents a valuable aid for diagnosing, evaluating, following-up and predicting response to therapy. 


\section{Appendix}

\section{Strength of recommendation ratings}

Type A. Strong positive recommendation, based on Class I evidence, or overwhelming Class II evidence.

Type B. Positive recommendation, based on Class II evidence.

Type C. Positive recommendation, based on strong consensus of Class III evidence.

Type D. Negative recommendation, based on inconclusive or conflicting Class II evidence.

Type E. Negative recommendation, based on evidence of ineffectiveness or lack of efficacy.

\section{Standards}

Generally accepted principles for patient management that reflect a high degree of clinical certainty (i.e., based on Class I evidence or, when circumstances preclude randomized clinical trials, overwhelming evidence from Class II studies that directly address the question at hand, or from decision-analysis that directly addresses all the issues).

\section{Guidelines}

Recommendations for patient management that may identify a particular strategy or range of management strategies that reflect moderate clinical certainty (i.e., based on Class II evidence that directly addresses the issue, decision analysis that directly addresses the issue, or strong consensus of Class III evidence).

\section{Practice options or advisories}

Other strategies for patient management for which there is some favorable evidence, but for which the community still considers this an option to be decided upon by individual practitioners.

\section{Practice parameters}

Results, in the form of one or more specific recommendations, from a scientifically-based analysis of a specific clinical problem.

\section{Quality of evidence ratings}

Class I. Evidence provided by one or more well-designed, prospective, blinded, controlled clinical studies.

Class II. Evidence provided by one or more well-designed clinical study such as case control, cohort studies, etc.

Class III. Evidence provided by expert opinion, non-randomized historical controls or case reports of one or more patients ${ }^{3}$. 


\section{References}

1. Kotchoubey B, Lang S, Mezger G, et al. Information processing in severe disorders of consciousness: vegetative state and minimally conscious state. Clin Neurophysiol 2005;116:2441-2453.

2. Assessment: EEG brain mapping. Report of the American Academy of Neurology, Therapeutics and Technology Assessment Subcommittee. Neurology 1989;39:1100-1101.

3. Nuwer M. Assessment of digital EEG, quantitative EEG, and EEG brain mapping: Report of the American Academy of Neurology and the American Clinical Neurophysiology Society. Neurology 1997;49:277-292. Current guideline. Reaffirmed on 02/09/2008.

4. Luccas FJC, Anghinah R, Braga NIO, et al. Recomendações para o Registro/Interpretação do Mapeamento Topográfico do Eletrencefalograma e Potenciais Evocados Parte II: Correlações Clínicas. Arq Neuropsiquiatr 1999;57:132-146.

5. Nuwer MR. Clinical use of QEEG. Clin Neurophysiol 2003; 114:2225.

6. Fumiharu T, Neil SC, Benjamin HN. Electroencephalogram characteristics of autonomic arousals during sleep in healthy men. Clin Neurophysiol 2006;117: 2597-2603.

7. Jennett B, Adams JH, Murray LS, Graham DI. Neuropathology in vegetative and severely disabled patients after head injury. Neurology 2001;56:486-490.

8. Borthwick CJ, Crossley R. Permanent vegetative state: usefulness and limits of a prognostic definition. NeuroRehabilitation 2004;19:381-389.

9. Davey MP, Victor JD, Schiff ND. Power spectra and coherence in the EEG of a vegetative patient with severe asymmetric brain damage. Clin Neurophysiol 2000;111:1949-1954.

10. Leon-Carrion J, Martin-Rodriguez JF, Damas-Lopez J, Barroso y Martin JM, Dominguez-Morales MR. Brain function in the minimally conscious state: A quantitative neurophysiological study. Clin Neurophysiol 2008;119:1506-1514.

11. John R, Prichep LS. The relevance of qEEG to the evaluation of behavioral disorders and pharmacological interventions. Clin EEG Neurosci 2006;37:135-143.

12. Furlan AJ, Henry CE, Sweeney PJ, Mitsumoto H. Focal EEG abnormalities in Heidenhains variant of Jakob-Creutzfeldt disease. Arch Neurol 1981;38:312-314.

13. Wieser HGr, Schindler K, Zumsteg D. EEG in CreutzfeldtJakob disease. Clin Neurophysiol 2006;117:935-951.

14. Jonkman J, Weerd AW, Poortvliet DCJ, et al. Neurometrics in cerebral ischemia and uremic encephalopathy. Brain Topogr 1992;4:277-284.

15. Doyle OM, Greene BR, Murray DM, Marnane L, Lightbody G, Boylan GB. The effect of frequency band on quantitative EEG measures in neonates with hypoxic-ischaemic encephalopathy. Conf Proc IEEE Eng Med Biol Soc 2007;2007:717-721.

16. Popkena RJ, Kropvelda D, Oostingb J, Chamuleau RAM. Quantitative Analysis of EEG Power Spectra in Experimen- tal Hepatic Encephalopathy. Neuropsychobiology 1983;9: 235-243.

17. Kullmann F, Hollerbach S, Lock G, Holstege A, Dierks T, Scholmerich J. Brain electrical activity mapping of EEG for the diagnosis of (sub)clinical hepatic encephalopathy in chronic liver disease. Eur J Gastroent Hepatol 2001;13:513-522.

18. Piero A, Quero JC, Del Piccolo F, Gatta A,d Schalm SW. Diagnostic tools for the detection of subclinical hepatic encephalopathy: comparison of standard and computerized psychometric tests with spectral-EEG. Metab Brain Dis 1996;11:315-327.

19. Newton T, Cook I, Kalechstein A, Duran S, Monroy F, Ling W, Leuchter A. Quantitative EEG abnormalities in recently abstinent methamphetamine dependent individuals. Clin Neurophysiol 2003;114;410-415.

20. Fakhourya T, Abou-Khalila B, Blumenkopf B. EEG changes in intrathecal baclofen overdose: a case report and review of the literature. Electroencephalogr Clin Neurophysiol 1998;107: 339-342.

21. Korinthenberg R, Scheuring B, Boos J, Niemeyer C. On the origin of EEG-slowing and encephalopathy during induction treatment of acute lymphoblastic leukemia. Med Pediatr Oncol 2002;39:566-572.

22. Bryan YG. The EEG in Coma. J Clin Neurophysiol 2000;17: 473-485.

23. Loganovsky KN, Yuryev KL. EEG Patterns in Persons Exposed to Ionizing Radiation as a Result of the Chernobyl Accident. Part 2: Quantitative EEG Analysis in Patients Who Had Acute Radiation Sickness. J Neuropsychiatry Clin Neurosci 2004; 16:70-82.

24. Jacobson SA, Leuchter AF, Walter DO. Conventional and quantitative EEG in the diagnosis of delirium among the elderly. J Neurol Neurosurg Psychiatry 1993;56:153-158.

25. Brenner RP M.D. Utility of EEG in Delirium: Past Views and Current Practice. Int Psychogeriatr 1991;3:211-229.

26. Thomas C, Hestermann U, Walther S, et al. Prolonged activation EEG differentiates dementia with and without delirium in frail elderly patients. J Neurol Neurosurg Psychiatry 2008 Feb 79 119-25.

27. Hughes JR, John ER: Conventional and quantitative electroencephalography in psychiatry. J Neuropsychiatry Clin Neurosci 1999;11:190-208.

28. Chabot RJ, di Michele F, Prichep LS: The role of quantitative electroencephalography in child and adolescent psychiatric disorders. Child Adolesc Psychiatr Clin N Am 2005;14:21-53.

29. The Value of Quantitative Electroencephalography in Clinical Psychiatry: A Report by the Committee on Research of the American Neuropsychiatric Association. J Neuropsychiatry Clin Neurosci 2006;18:460-500.

30. Klimesch W. EEG alpha and theta oscillations reflect cognitive and memory performance: a review and analysis. Brain Res Rev 1999;29:169-195. 
31. Jausovec N, Jausovec K. Spatiotemporal brain activity related to intelligence: a low resolution brain electromagnetic tomography study. Brain Res Cogn Brain Res 2003;16:267-272.

32. Marosi E, Rodriguez H, Harmony T, et al. Broad band spectral parameters correlated with different I.Q. measurements. Int J Neurosci 1999;97:17-27.

33. Anokhin AP, Lutzenberger W, Birbaumer N. Spatiotemporal organization of brain dynamics and intelligence: an EEG study in adolescents. Int J Psychophysiol 1999;33:259-273.

34. Lutzenberger W, Birbaumer N, Flor H, Rockstroh B, Elbert T. Dimensional analysis of the human EEG and intelligence. Neurosci Lett 1992;143:10-14.

35. Neubauer AC, Grabner RH, Freudenthaler HH, Beckmann JF, Guthke J. Intelligence and individual differences in becoming neurally efficient. Acta Psychol (Amsterdam) 2004; 116:55-74

36. Barry RJ, Clarke AR, McCarthy R, Selikowitz M. EEG coherence attention-deficit/hyperactivity disorder: a comparative study DSM-IV types. Clin Neurophysiol 2002;113:579-85.

37. Martin-Loeches M, Munoz-Ruata J, Martinez-Lebrusant L, Gomez-Jari G. Electrophysiology and intelligence: the electrophysiology of intellectual functions in intellectual disability. J Intellect Disabil Res 2001;45:63-75.

38. Schmid RG, Tirsch WS, Scherb H. Correlation between spectral EEG parameters and intelligence test variables in schoolage children. Clin Neurophysiol 2002;113:1647-56.

39. Posthuma D, Neale MC, Boomsma DI, de Geus EJ. Are smarter brains running faster? Heritability of alpha peak frequency, IQ, and their interrelation Behav Genet 2001;31:567-79.

40. Jausovec N, Jausovec K. Differences in EEG current density related to intelligence. Brain Res Cogn Brain Res 2001;12:55-60.

41. Becker J, Velasco M, Harmony T. Electroencephalographic characteristics of children with learning disabilities. Clin Electroencephalogr 1987;18:93-101.

42. Kaye H, John ER, Ahn H, et al. Neurometric evaluation of learning disabled children. Int J Neurosci 1981;13:15-25.

43. Gasser T, Rousson V, Gasser US. EEG Power and Coherence in Children with Educational Problems. J Clin Neurophysiol 2003;20:273-282.

44. Thatchera RW, Northa D, Biver C. EEG and intelligence: Relations between EEG coherence, EEG phase delay and power. Clin Neurophysiol 2005;116:2129-2141.

45. Silberstein RB, Song J, Nunez PL, Park W. Dynamic sculpting of brain functional connectivity is correlated with performance. Brain Topogr 2004;16:249-54.

46. Klimesch W, Doppelmayr M, Rohm D, Pollhuber D, Stadler W. Simultaneous desynchronization and synchronization of different alpha responses in the human electroencephalograph: a neglected paradox? Neurosci Lett 2000;284:97-100.

47. Klimesch W, Schack B, Schabus M, Doppelmayr M, Gruber M, Saunseng R. Phase-locked alpha and theta oscillatins generate the P1-N1 complex and are related to memory performance. Brain Res Cogn 2004;19:302-16.

48. John ER. The neurophysics of consciousness. Brain Res Rev 2002;39:1-28.

49. American Academy of Pediatrics. Clinical practice guideline: diagnosis and evaluation of the child with attention-deficit/ hyperactivity disorder. Pediatrics 2000;105:1158-1170.

50. Bresnahan SM, Anderson JW, Barry RJ. Age related changes in quantitative EEG in attention deficit hyperactivity disorder. Biol Psychiatry 1999;46:1690-1697.

51. Bresnahan SM, Barry RJ. Specificity of quantitative EEG analysis in adults with attention deficit hyperactivity disorder. Psychiatry Res 2002;112:133-144.

52. Snyder SM, Hall JR. A meta-analysis of quantitative EEG power associated with attention-deficit hyperactivity disorder. J Clin Neurophysiol 2006;23:440-455.

53. Coutin-Churchman P, Anez Y, Uzcategui M, et al. Quantitative spectral analysis of EEG in psychiatry revisited: drawing signs out of numbers in a clinical setting. Clin Neurophysiol 2003;114:2294-2306.

54. Holschneider DP, Leuchter AF. Clin Neurophysiol using electroencephalography in geriatric psychiatry: neurobiologic implications and clinical utility. J Geriatr Psychiatr Neurol 1999;12:150-164.

55. Hunter AM, Cook IA, Leuchter AF. The promise of the quantitative electroencephalogram as a predictor of antidepressant treatment outcomes in major depressive disorder. Psychiatr Clin North Am 2007;30:105-124.

56. Spronk D, Arns M, Bootsma A, van Ruth R, Fitzgerald PB. Long-term effects of left frontal rTMS on EEG and ERPs in patients with depression. Clin EEG Neurosci 20081;39: 118-124.

57. Pozzi D, Golimstock A, Petracchi M, García H, Starkstein S. Quantified electroencephalographic changes in depressed patients with and without dementia. Biol Psychiatry 1995; 38:677-683.

58. Morgan ML, Cook IA, Rapkin AJ, Leuchter AF. Neurophysiologic changes during estrogen augmentation in perimenopausal depression. Maturitas 2007;56:54-60.

59. Morgan ML, Witte EA, Cook IA, Leuchter AF, Abrams M, Siegman B. Influence of age, gender, health status, and depression on quantitative EEG. Neuropsychobiology 2005;52:71-76.

60. Koek RJ, Yerevanian BI, Tachiki KH, Smith JC, Alcock J, Kopelowicz A. Hemispheric asymmetry in depression and mania. A longitudinal qEEG study in bipolar disorder. J Affect Disord 1999;53:109-122.

61. Leuchter AF, Cook IA, Uijtdehaage $\mathrm{SH}$, et al. Brain structure and function and the outcomes of treatment for depression. J Clin Psychiatry 1997;58(Suppl 16):22-31.

62. Lieber AL. Diagnosis and subtyping of depressive disorders by quantitative electroencephalography: II. Interhemispheric measures are abnormal in major depressives and frequency 
analysis may discriminate certain subtypes. Hillside J Clin Psychiatry 1988;10:84-97.

63. Kwon JS, Youn T, Jung HY. Right hemisphere abnormalities in major depression: quantitative electroencephalographic findings before and after treatment. J Affect Disord 1996;40:169-173.

64. Pozzi D, Golimstock A, Migliorelli R, Tesón A, García H, Starkstein S. Quantified electroencephalographic correlates of depression in Alzheimer's disease. Biol Psychiatry 1993; 34:386-391.

65. Lieber AL, Prichep LS. Diagnosis and subtyping of depressive disorders by quantitative electroencephalography: I. Discriminant analysis of selected variables in untreated depressives. Hillside J Clin Psychiatry 1988;10:71-83.

66. Lieber AL, Newbury ND. Diagnosis and subtyping of depressive disorders by quantitative electroencephalography: III. Discriminating unipolar from bipolar depression. Hillside J Clin Psychiatry 1988;10:165-72.

67. Lieber AL, Newbury ND. Diagnosis and subtyping of depressive disorders by quantitative electroencephalography: IV. Discriminating subtypes of unipolar depression. Hillside J Clin Psychiatry 1988;10:173-82.

68. Kenneth J. Continuous EEG Monitoring in the Neuroscience Intensive Care Unit and Emergency Department. Journal of Clinical Neurophysiology. Intensive Care EEG Monitoring 1999;16:14-39.

69. Papadelis C, Maglaveras N, Kourtidou-Papadeli C, et al. Quantitative multichannel EEG measure predicting the optimal weaning from ventilator in ICU patients with acute respiratory failure. Clin Neurophysiol 2006;117: 752-770.

70. Scheuer ML and Wilson SB. Data Analysis for Continuous EEG Monitoring in the ICU: Seeing the Forest and the Trees. J Clin Neurophysiol 2004;21:353-378.

71. Nuwer MR, Comi G, Emerson R, Fuglsang-Frederiksen J, Guérit M, Hinrichs H, Ikeda A, Luccas FJC, Rappelsberger P. IFCN standards for digital recording of clinical EEG. Electroencephalogr Clin Neurophysiol 1998;106:259-261.

72. Klass DW, Brenner RP. Electroencephalography of the elderly. J Clin Neurophysiol 1995;12:116-131.

73. Sandmann MC, Piana ER, Sousa DS, Bittencourt PRM. (1996) Eletrencefalograma digital com mapeamento em demência de Alzheimer e doença de Parkinson. Arq Neuropsiquiatr 1996;54:50-56.

74. Lehmann, D. Multichannel topography of human alpha EEG fields. Electroenceph Clin Neurophysiol 1971; 31:439-449.

75. Duffy FH, Burchfiel JL, Lombroso CT. Brain electrical activity mapping (BEAM): A method for extending the clinical utility of EEG and evoked potential data. Ann Neurol 1979;5:309-321.

76. Loeches MM, Gil P, Jimenez F, et al. Topographic maps of brain electrical activity in primary degenerative dementia of
Alzheimer type and multi-infarct dementia. Biol Psych 1991; 29:211-223

77. Saletu B, Paulus E, Grunbergerer J. Correlation maps: on the relation of electroencephalographic slow wave activity to computerized tomography and psycopathometric measurements in dementia. In: Maurer K. Imaging of Brain in Psychiatry and Related Fieldsed. Berlin: Springer-Verlag; 1993; 263-265.

78. Pucci E, Belardinelli N, Cacchiò G, Signorino M, Angeleri F. EEG power spectrum differences in early and late onset forms of Alzheimer's disease. Clin Neurophysiol 1999;110:621-631.

79. Dierks T, Perisic I, Frölich L, Ihl R, Maurer K. Topography of the qEEG in dementia of Alzheimer type: relation to severity of dementia. Psych Research 1991;40:181-194.

80. Leuchter AF, Cook IA, Newton TF, et al. Regional differences in brain electrical activity in dementia: use of spectral power and spectral ratio measures. Electroencephalogr Clin Neurophysiol 1993;87:385-393.

81. Anderer P, Saletu B, Klöppel B, Semlitsch HV, Werner H. Discrimination between demented patients and normals based on topographic EEG slow wave activity: comparison between $\mathrm{z}$ statistics, discriminant analysis and artificial neural network classifiers. Electroencephalogr clin Neurophysiol 1994;91: 108-117.

82. Claus JJ, Strijers RLM, Jonkman EJ, et al. The diagnostic value of EEG in mild senile alzheimer's disease. Clin Neurophysiol 1999;110:825-832.

83. Nielsen T, Montplaisir J, Lassonde M. Decreased Interhemispheric EEG Coherence during sleep in agenesis of the corpus callosum. Eur Neurol 1993;33:173-176.

84. Leuchter AF, Spar JE, Walter DO, Weiner H. Electroencephalographic spectra and coherence in the diagnosis of Alzheimer"s-type and multi-infarct dementia. Arch Gen Psychiatry 1987;44:993-998.

85. Besthorn C, Zerfass R, Geiger-Kabisch C, et al. Discrimination of $\mathrm{AD}$ and normal aging by EEG data. Electroencephalogr. Clin Neurophysiol 1997;103:241-248.

86. Locatelli T, Cursi M, Liberati D, Franceschi M, Comi G. EEG coherence in Alzheimer's disease. Electroencephalogr. Clin Neurophysiol 1998;106:229-237.

87. Projeto Diretrizes - Associação Médica Brasileira e Conselho Federal de Medicina. Fonseca LC. Demência - Eletroencefalograma e eletroencefalograma quantitativo. Final Preparation: May 15, 2008. Available at URL address:http://www.projetodiretrizes.org.br/projeto_diretrizes/035.pdf

88. U.S. Food and Drug Administration (FDA) (Centers for Devices and Radiological Health. NeuroGuide Analysis System (NAS). Updated Oct 2005. Available at URL address: http:// www.fda.gov. 